ease, as measured by the time from motor onset to death (and therefore not biased by studying primarily living subjects). ${ }^{5}$ We have not examined the shorter HD CAG repeat for any specific measures of progression and therefore cannot exclude it as a factor in this process, which is clearly distinct from the process that leads to motor onset.

Finally, we showed that using genotypic extremes in an inappropriate statistical paradigm can lead to false-positive results. This can negatively influence the time, energy, and funds expended on false leads. It does not deny the potential value of extreme individuals, but simply indicates that another mode of analysis is required to reach definitive conclusions from such individuals.

Copyright (C) 2012 by AAN Enterprises, Inc.

1. Lee JM, Ramos EM, Lee JH, et al. CAG repeat expansion in Huntington disease determines age at onset in a fully dominant fashion. Neurology 2012;78:690-695.

2. Aziz NA, Jurgens CK, Landwehrmeyer GB, et al. Normal and mutant HTT interact to affect clinical severity and progression in Huntington disease. Neurology 2009;73:12801285.

3. Squitieri F, Gellera C, Cannella M, et al. Homozygosity for CAG mutation in Huntington disease is associated with a more severe clinical course. Brain 2003;126:946-955.

4. Ross OA, Singleton AB. Does trans size matter in Huntington disease? Neurology 2012;78:686-687.

5. Gusella JF, Persichetti F, MacDonald ME. The genetic defect causing Huntington's disease: repeated in other contexts? Mol Med 1997;3:238-246.

\section{THE TREMOR NETWORK TARGETED BY SUCCESSFUL VIM DEEP BRAIN STIMULATION IN HUMANS}

Fan-gang Meng, Jian-guo Zhang, Beijing, China; C. Chris Kao, Nashville, TN: Klein et al. ${ }^{1}$ provide evidence that the network of structural connectivity can be reconstructed from stimulation contact sites to remote targets in deep brain stimulation (DBS) of the ventral intermediate nucleus of thalamus (VIM) in humans. Essential tremor (ET) is the most common tremor disorder and Parkinson disease (PD) is often accompanied by tremors. ET and PD can both can be treated with DBS but the difference is that STN was used as a target in PD and VIM in ET. There is evidence that STN stimulation-induced motor improvement was sustained at 10 years in $\mathrm{PD},{ }^{2}$ and habituation of tremor suppression can be developed in VIM-DBS in ET. ${ }^{3}$ As the stimulation effect of the 2 targets is different, the mechanisms must be investigated. In addition, the differences in the reproducible networks of structural connectivity must be determined. Subthalamic nucleus (STN) and VIM stimulation activate different remote targets, and this might relate to the tolerance of VIM-DBS in ET but long-term effect of STN-DBS in PD. Further studies are needed to explore the reproducible network reconstruction of STN and VIM and to understand the mechanism of stimulation.

\section{Author Response: Johannes C. Klein, Rudiger} Hilker, Frankfurt, Germany: We thank Meng et al. for their interest in our work. Stimulation of VIM and STN produces significantly different clinical results, along with a different spectrum of side effects.

It is likely that these observations are due to differences of the neuronal circuitry, including remote connections of these regions. Optogenetic studies in parkinsonian rodents have found that stimulation of axons projecting to the STN, in contrast to stimulation of its cell bodies, mediates suppression of motor symptoms. ${ }^{4}$ This study underlines the importance of modulating the STN's connectional network for clinical efficacy in the treatment of PD.

A diffusion tractography study analyzed remote connections of the STN in a set of normal volunteers. ${ }^{5}$ The authors reconstructed a remote network of connectivity that is very different from the VIM network, and comparable to previous studies of STN connectivity in nonhuman animals. These differences between VIM and STN networks may explain the disparate clinical effects of DBS of these targets. However, data regarding the connectivity of the target point in STN patients are not yet available.

Copyright (c) 2012 by AAN Enterprises, Inc.

1. Klein JC, Barbe MT, Seifried C, et al. The tremor network targeted by successful VIM deep brain stimulation in humans. Neurology 2012;78:787-795.

2. Castrioto A, Lozano AM, Poon YY, Lang AE, Fallis M, Moro E. Ten-year outcome of subthalamic stimulation in Parkinson disease: a blinded evaluation. Arch Neurol 2011; 68:1550-1556.

3. Barbe MT, Liebhart L, Runge M, et al. Deep brain stimulation in the nucleus ventralis intermedius in patients with essential tremor: habituation of tremor suppression. J Neurol 2011;258:434-439.

4. Gradinaru V, Mogri M, Thompson KR, Henderson JM, Deisseroth K. Optical deconstruction of parkinsonian neural circuitry. Science 2009;17:324:354-359.

5. Aravamuthan BR, Muthusamy KA, Stein JF, Aziz TZ, Johansen-Berg H. Topography of cortical and subcortical connections of the human pedunculopontine and subthalamic nuclei. Neuroimage 2007;37:694-705. 


\section{Neurology}

The tremor network targeted by successful VIM deep brain stimulation in humans

Fan-gang Meng, Johannes C. Klein, Jian-guo Zhang, et al.

Neurology 2012;79;953

DOI 10.1212/01.wnl.0000419345.94406.07

This information is current as of August 27, 2012

\section{Updated Information \&} Services

References

Permissions \& Licensing

Reprints including high resolution figures, can be found at: http://n.neurology.org/content/79/9/953.full

This article cites 5 articles, 1 of which you can access for free at: http://n.neurology.org/content/79/9/953.full\#ref-list-1

Information about reproducing this article in parts (figures,tables) or in its entirety can be found online at:

http://www.neurology.org/about/about_the_journal\#permissions

Information about ordering reprints can be found online: http://n.neurology.org/subscribers/advertise

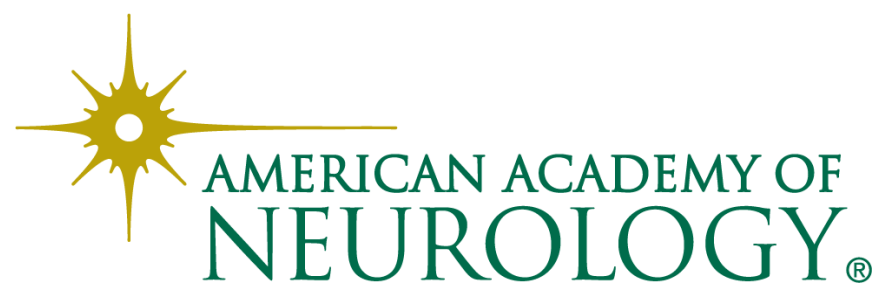

